\title{
Development and Validation of Reverse Phase Liquid Chromatography Method for Estimation of Losartan in Bulk Drug.
}

\author{
Dr. Anita shinde ${ }^{1}$, Dr. Suman Malik ${ }^{2}$, Dr. K. C. Asati, Amit Asati ${ }^{2}$ \\ ${ }^{1}$ (Department of chemistry I.E.H.E, Bhopal, \\ ${ }_{2}^{2}$ (Department of chemistry Sadhu Vaswani college Bairagarh, Bhopal,
}

\begin{abstract}
A simple, precise and reversed phase liquid chromatographic method was developed and it is validated for estimation of losartan in bulk drug. Losartan is use for treatment of hypertension. The separation was achieved on Acquity BEH C18 $1.7 \mu,(2.1 \mathrm{X} 100) \mathrm{mm}$, analytical column with mobile phase consisted of buffer (adjust pH 3.0 of water with dilute formic acid) : Acetonitrile $(50: 50 \mathrm{v} / \mathrm{v})$ at isocratic flow of $0.3 \mathrm{ml} / \mathrm{min}$ with UV detection wavelength was at $230 \mathrm{~nm}$. The method was successfully validated in accordance to ICH guidelines for accuracy, precision, specificity, linearity. The linear regression analysis data for calibration plots showed good linear relationship in the concentration range $25-75 \mu \mathrm{g} / \mathrm{mL}$ for losartan. The \% Recovery/Accuracy was within the range between $98 \%$ and $102 \%$. The percentage RSD for precision method was found to be less than $2 \%$. The method was successfully applied for routine analysis of losartan in bulk samples.
\end{abstract}

Keywords: Assay, ICH, Isocratic, Liquid Chromatography, validation

\section{Introduction}

Losartan is an angiotensin II receptor antagonist drug to be marketed. It is chemically described as a (2butyl-4-chloro-1-\{[2'-(1H-testrazol-5-yl)biphenyl-4-yl]methyl $\}-1 \mathrm{H}$-imidazol-5-yl)methanol. Its empirical formula is $\mathrm{C}_{22} \mathrm{H}_{23} \mathrm{ClN}_{6} \mathrm{O}$, and the chemical structural is shown in fig-I. Losartan is a white crystalline powder with a molecular weight of 422.9. It is orally active non-peptide angiotensin II (Type AT1) receptor antagonists, losartan is indicated for the treatment of hypertension. It may also delay progression of diabetic nephropathy, and is also indicated for the reduction of renal disease progression in patients with type 2 diabetes. $^{[1-4]}$

The objective of validation of an analytical procedure is to demonstrate that it is suitable for its intended purpose. The intended use of analytical methods is to assess product quality and validation is the process of generating experimental data that provides evidence that the performance of an analytical method is adequate for reliably assessing product quality. ${ }^{[5-8]}$ Method validation acceptance criteria necessarily reflect what we believe is "adequate performance." The validation procedure has been performed by using ultra performance liquid chromatography. The method has been validated for linearity, precision (system repeatability, method repeatability, and method reproducibility), accuracy, range, specificity, and solution stability. ${ }^{[9-11]}$ Literature survey indicates that there is no RP-LC short run time method available for assay determination of Losartan, ${ }^{[12-}$ 15] thus we aimed to develop it. Liquid chromatography is a new technique used in analytical chemistry for separating and analyzing substances. Chromatography depends on the distribution of the mixture between two phases, one of them is fixed and is called Stationary phase while the other is not fixed and is called the Mobile phase. The mixture is dissolved in the moving phase and passed over a stationary phase. When a mixture of components is introduced in to a LC column, they travel according to their relative affinities towards the stationary phase. The component which has more affinity towards the adsorbent travels slower. The component which has less affinity towards the stationary phase travels faster. Since no two components have the same affinity towards the stationary phase, the components are separated ${ }^{[15-19]}$ Use this separation technique and developed new very short run time method and validate as per USP and ICH guidelines.

\section{Experimental}

\subsection{Methods and material}

2.1.1 Chemicals and reagents Pure samples of losartan were obtained as gift. LC grade Acetonitrile, and formic acid were purchased from Merck Company Mumbai. High purity deionised water was obtained from [Millipore, Milli-Q] purification system.

2.1.2 LC instrumentation and conditions The analysis of the drug was carried out on a Waters Acquity UPLC (Ultra performance liquid chromatography) Binary Gradient System, $10 \mu \mathrm{L}$ injection loop column with auto injector. Column compartment having temperature control and for detection Ultraviolet Detector was employed throughout the analysis. 
2.1.3 Chromatographic conditions Acquity BEH 1.7 $\mu$, (2.1 X 100) mm, Make: Waters, analytical column was used for separation. Column temperature was $40^{\circ} \mathrm{C}$. Mobile phase consisted of buffer (Adjust $\mathrm{pH} 3.0$ of water with dilute formic acid) : Acetonitrile (50:50 v/v). Mix well and filter through $0.22 \mu \mathrm{m}$ filter. The mobile phase was prepared freshly and degassed by sonicating for $5 \mathrm{~min}$ before use. Water : Methanol (90:10 v/v) was used as diluent. The analysis was done on isocratic flow of $0.3 \mathrm{ml} / \mathrm{min}$ with UV detection wavelength was performed at $230 \mathrm{~nm}$ at $15^{\circ} \mathrm{C}$ temperature using $3.0 \mu \mathrm{L}$ injection volumes with auto injector.

2.1.4 Stock and working standard solutions Accurately weigh and transfer $25 \mathrm{mg}$ of losartan working standard into a $50 \mathrm{~mL}$ volumetric flask, add about $30 \mathrm{~mL}$ of diluent and sonicate to dissolve it completely and make volume up to the mark with the same. Further pipette out $5 \mathrm{~mL}$ of the above stock solution into a $50 \mathrm{~mL}$ volumetric flask and dilute up to the mark with diluent. Mix well and filter through $0.22 \mu \mathrm{m}$ filter. Obtain solution concentration was $50 \mu \mathrm{g} / \mathrm{ml}$.

2.1.5 Assay of losartan sample Accurately weigh and transfer equivalent to $25 \mathrm{mg}$ of losartan sample into a $50 \mathrm{~mL}$ volumetric flask, add about $30 \mathrm{~mL}$ of diluent and sonicate to dissolve it completely and make volume up to the mark with the same. Further pipette out $5 \mathrm{~mL}$ of the above stock solution into a $50 \mathrm{~mL}$ volumetric flask and dilute up to the mark with diluent. Mix well and filter through $0.22 \mu \mathrm{m}$ filter. Obtain solution concentration was $50 \mu \mathrm{g} / \mathrm{ml}$. This solution was injected into LC system. For the determination, Peak area of losartan was measured. Calculate \% Losartan by following formulae.

Where,

$$
\operatorname{LOSARTAN}(\%)=\frac{\mathrm{A}_{1} \mathrm{X} \mathrm{C}_{2}}{-\mathrm{A}_{2} \mathrm{X} \mathrm{C}_{1}}
$$

"Equation 1"

$\mathrm{A}_{1}=$ Area of Losartan in sample

$\mathrm{A}_{2}=$ Area of Losartan in standard

$\mathrm{C}_{1}=$ Concentration of Losartan in sample $(\mathrm{mg} / \mathrm{ml})$

$\mathrm{C}_{2}=$ Concentration of Losartan in Standard $(\mathrm{mg} / \mathrm{ml})$

$\mathrm{P}=$ Potency of Standard

\subsection{Method Validation}

The objective of the method validation is to demonstrate that the method is suitable for its intended purpose as it is stated in ICH guidelines. The method was validated for linearity, precision (repeatability and intermediate precision), accuracy, specificity, stability and system suitability.

2.2.1 Linearity The linearity of an analytical procedure is its ability to elicit test results that are directly, or by a well-defined mathematical transformation, proportional to the concentration of analyte in sample within a given range. It should be established initially by visual examination of a plot of signals as a function of analyte concentration of content. If there appears to be a linear relationship, test results should be established by appropriate statistical methods (e.g., by calculation of a regression line by the method of least squares).

Five standard solutions of Losartan were prepared from three stocks in the range of $50 \%$ to $150 \%$ of the nominal concentration and injected once. Linearity regression analysis demonstrated the acceptability of the method for quantitative determination of Losartan over the concentration range of about $25 \mathrm{ppm}$ to $75 \mathrm{ppm}$ of the nominal concentration. Linearity graph was shown in fig-2 and slope, intercept correlation factor and Regression equation were shown in table-I.

2.2.2 Precision The precision of an analytical method is the degree of agreement among individual test results when the method is applied repeatedly to multiple samplings of a homogeneous sample. The precision of an analytical method is usually expressed as the standard deviation or relative standard deviation (coefficient of variation) of a series of measurements. Precision may be a measure of either the degree of reproducibility or repeatability of the analytical method under normal operating conditions. The ICH documents recommend that repeatability should be assessed using a minimum of nine determinations covering the specified range for the procedure (i.e., three concentrations and three replicates of each concentration, or a minimum of six determinations at $100 \%$ of the test concentration).

2.2.2.1 System Repeatability Standard solution is prepared 50ppm were injected in six times and RSD of areas and retention times were calculated. The percentage RSD of areas was less than $1.0 \%$. Result are presented in table-2 
2.2.2.2 Method repeatability Six preparation of Losartan sample was analyzed from sample preparation to final results by the same analyst and the percentage RSD of obtained results was less than $2 \%$ and obtained result were within given range $100 \pm 2$. Result are presented in table-3

2.2.3 System Reproducibility Three Losartan sample are analysed by this method in duplicate preparation and obtain result are in table-4

2.2.4 Accuracy It is defined as the closeness of test results obtained by the method to the true value. It may often be expressed as percent recovery by the assay of known, added amounts of analyte. Accuracy is a measure of the exactness of the analytical method. The ICH documents recommend that accuracy be assessed using a minimum of nine determinations over a minimum of three concentration levels, covering the specified range (i.e., three concentrations and three replicates of each concentration). The three different concentrations of Losartan standard solutions were determined from three replicate injections, using the linear regression lines (linearity section). The deviations of the obtained results (expressed as percentage accuracy) were calculated from the true values were presented in table-5.

Each deviation should be calculated according to the following formula:

$$
d=\frac{\text { Calculated }- \text { Added }}{\text { Added }} * 100
$$

"Equation 2"

The average deviations from true value are less than $2.0 \%$.

2.2.5 Specificity The ICH documents define specificity as the ability to assess unequivocally the analyte in the presence of components that may be expected to be present, such as impurities, degradation products, and matrix components. In an assay, demonstration of specificity requires that it can be shown that the procedure is unaffected by the presence of impurities or excipients The specificity of the method was verified by testing the blank, standard and sample (un-spiked and spiked), determined the resolution factors between analyte peak (Losartan) and the nearest peak. Sample of Losartan sample spiked with Losartan diamide impurity.

No significant interfering peak appeared in the blank, System suitability and standard chromatogram at the retention times of the analyte peaks.

2.2.6 Range The range obtained from Linearity, Precision and Accuracy is summarized - ibesartan-25ppm to $75 \mathrm{ppm}$ ( $50 \%$ to $150 \%$ of nominal sample concentration)

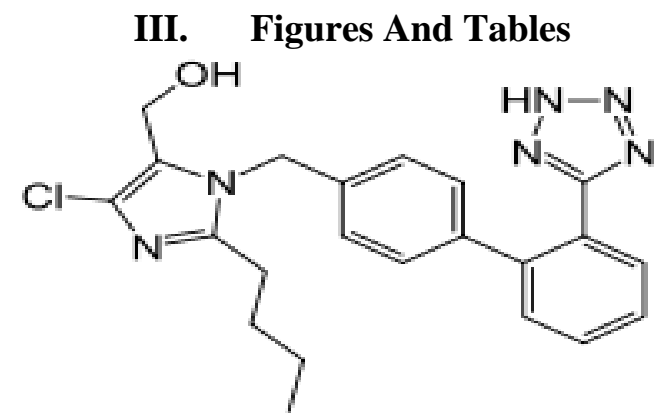

Fig-I losartan chemical structure

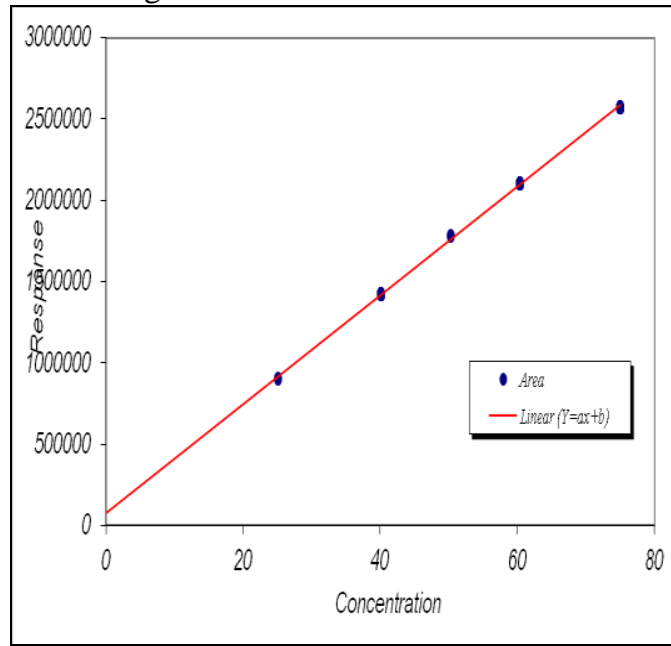


Fig-2 linearity graph

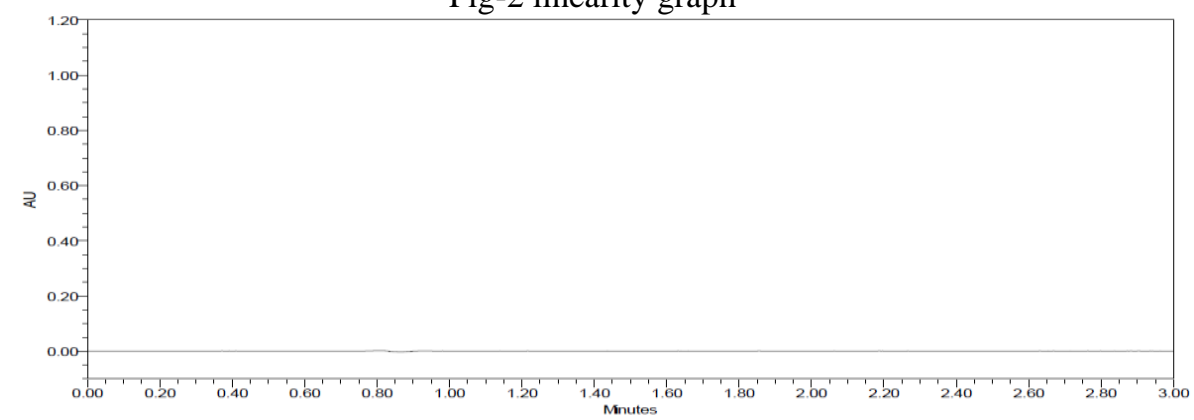

Fig-3 Typical Blank Chromatogram

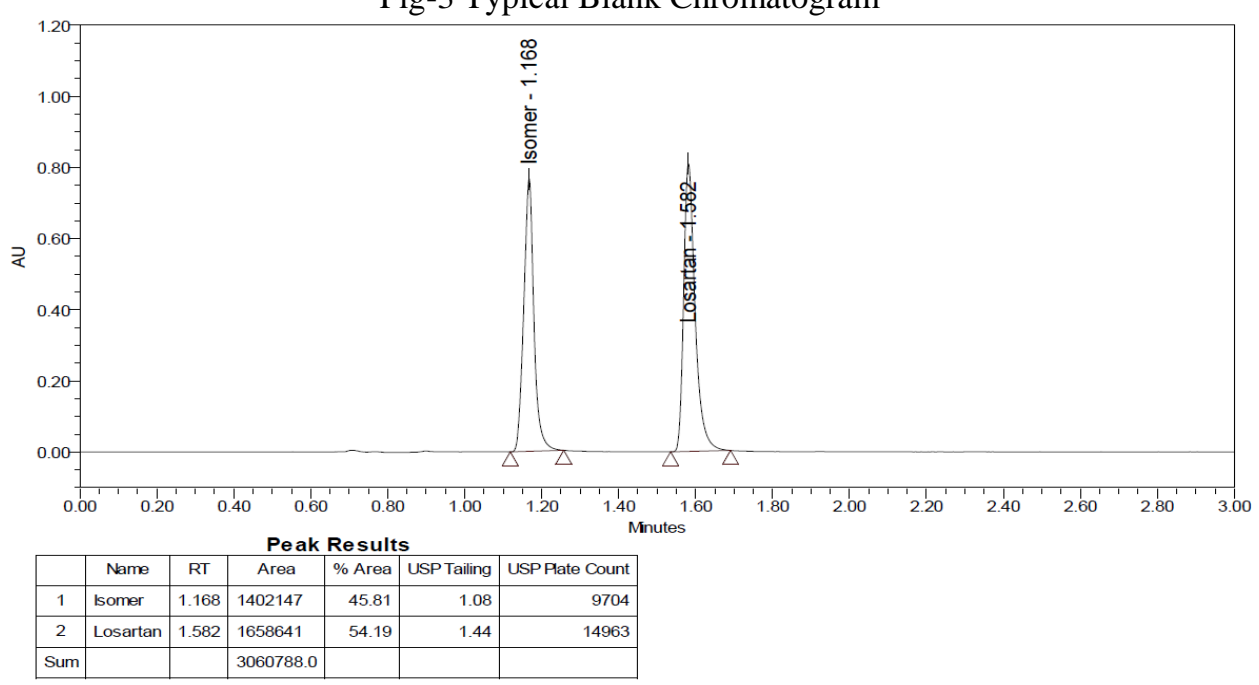

Fig-4 Typical System Suitability Chromatogram

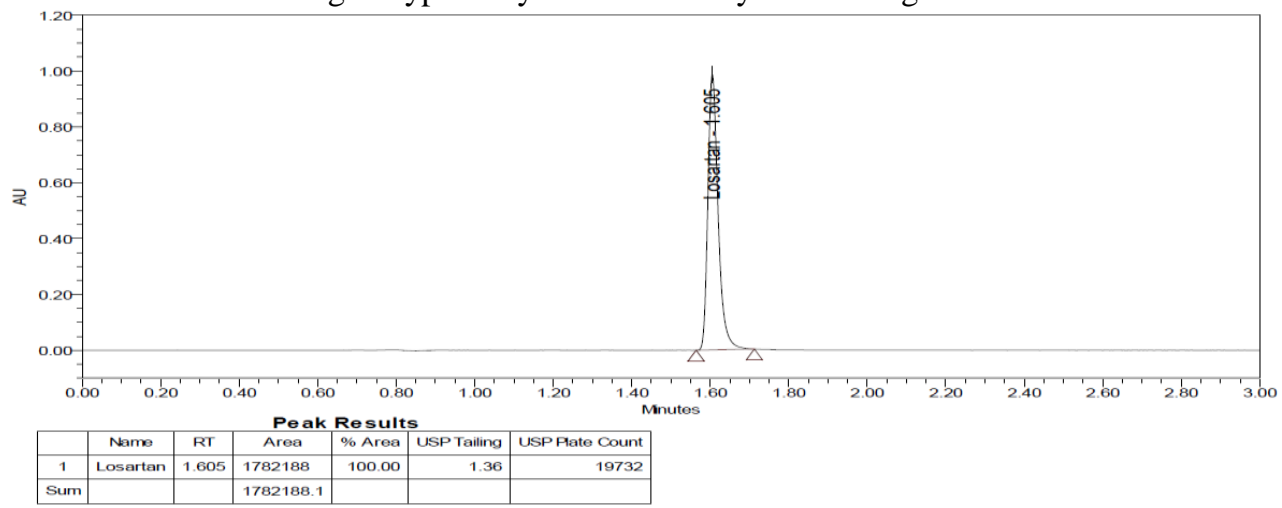

Fig-5 Typical Standard Chromatogram (50ppm)

\begin{tabular}{|c|c|}
\hline Losartan Concentration(ppm) & Losartan Area \\
\hline Slope & 33447 \\
\hline Intercept & 78179 \\
\hline Correlation factor & 0.999 \\
\hline
\end{tabular}

Table-1 Linearity Data

\begin{tabular}{|c|c|}
\hline \multicolumn{2}{|c|}{ System Repeatability } \\
\hline Concentration (ppm) & Area \\
\hline 50.60 & 1782188 \\
\hline 50.60 & 1785896 \\
\hline 50.60 & 1780652 \\
\hline 50.60 & 1777835 \\
\hline 50.60 & 1775957 \\
\hline 50.60 & 1724026 \\
\hline Average & 1771092 \\
\hline STDEV & 23315.308 \\
\hline \%RSD & 1.316 \\
\hline
\end{tabular}


Table-2 System Repeatability data

\begin{tabular}{|c|c|c|c|}
\hline \multicolumn{2}{|c|}{ Method Repeatability } \\
\hline Concentration (ppm) & Retention time (min) & Area & \% Losartan \\
\hline 50.28 & 1.590 & 1769471 & 100.6 \\
\hline 50.22 & 1.589 & 1766449 & 100.5 \\
\hline 50.34 & 1.584 & 1769776 & 100.5 \\
\hline 50.26 & 1.584 & 176821 & 100.4 \\
\hline 50.30 & 1.585 & 1766448 & 100.4 \\
\hline 50.22 & 1.587 & 1764657 & 100.5 \\
\hline Average & 1.587 & & 0.085 \\
\hline STDEV & 0.003 & & 0.084 \\
\hline \%RSD & 0.163 & & \\
\hline
\end{tabular}

Table-3 Method Repeatability data

\begin{tabular}{|c|c|c|c|c|}
\hline \multicolumn{5}{|c|}{ Method Reproducibility } \\
\hline S No. & Concentration (ppm) & Area & \% Losartan & $\begin{array}{c}\text { \% Losartan } \\
\text { Average }\end{array}$ \\
\hline Sample-I Pre-I & 50.72 & 1765089 & 99.61 & \multirow{2}{*}{99.4} \\
\cline { 1 - 3 } Sample-I Pre-II & 49.62 & 1719240 & 99.14 & \multirow{2}{*}{99.2} \\
\cline { 1 - 3 } Sample-II Pre-I & 50.00 & 1728259 & 98.92 & \multirow{2}{*}{99.6} \\
\hline Sample-II Pre-II & 50.94 & 1768855 & 99.51 & 99.65 \\
\hline Sample-III Pre-I & 50.98 & 1772343 & 99.48 & \\
\hline Sample-III Pre-II & 51.12 & 1774123 & & \\
\hline
\end{tabular}

Table-4 Method Reproducibility data

\begin{tabular}{|c|c|c|c|c|c|}
\hline $\begin{array}{l}\text { Injection } \\
\text { No }\end{array}$ & Level & $\begin{array}{l}\text { Concentration } \\
(\mathrm{ppm})\end{array}$ & Area & $\begin{array}{c}\text { Calculated } \\
\text { concentration }(\mathrm{ppm})\end{array}$ & $\begin{array}{l}\text { Accuracy } \\
(\%)\end{array}$ \\
\hline 1 & \multirow{3}{*}{$80 \%$} & \multirow{3}{*}{40.10} & 1417847 & 40.05 & 99.90 \\
\hline 2 & & & 1420881 & $40 . .14$ & 100.12 \\
\hline 3 & & & 1411704 & 39.87 & 99.44 \\
\hline Average & & & 1416811 & & 99.8 \\
\hline 1 & \multirow{3}{*}{$100 \%$} & \multirow{3}{*}{50.28} & 1782188 & 50.95 & 101.33 \\
\hline 2 & & & 1785896 & 51.06 & 101.55 \\
\hline 3 & & & 1769776 & 50.58 & 100.59 \\
\hline Average & & & 1779287 & & 101.2 \\
\hline 1 & \multirow{3}{*}{$120 \%$} & \multirow{3}{*}{$59 . .98$} & 2103248 & 60.55 & 100.97 \\
\hline 2 & & & 2100269 & 60.46 & 99.97 \\
\hline 3 & & & 2106833 & 60.65 & 100.29 \\
\hline Average & & & 2103450 & & 101.1 \\
\hline
\end{tabular}

Table-5 Accuracy test data of Losartan

\section{Conclusion}

The finally method developed and validation demonstrated that The Method "Determination of Losartan Assay content by liquid Chromatography as per united state of pharmacopeia (USP) and international conference on harmonisation (ICH) guideline. it is selective, precise, linear, and accurate for performing the determination over the required concentration ranges of 50 to150\% of Losartan nominal sample concentration with very short analysis time that is 3 minutes.

\section{Reference}

[1]. Brenner BM, Cooper ME, de Zeeuw D. Effects of losartan on renal and cardiovascular outcomes in patients with type 2 diabetes and nephropathy. N Engl J Med 2001;345:861-9.

[2]. Sleight P, Yusuf S, Pogue J. Blood-pressure reduction and cardiovascular risk in the HOPE study. Lancet 2001;358:2130-1.

[3]. Wright JT Jr, Bakris G, Greene T. Effect of blood pressure lowering and antihypertensive drug class on progression of hypertensive kidney disease: Results from the AASK trial. J Am Med Assn 2002;288:2421-31.

[4]. McCarthy KE, Wang Q, Tsai EW, Gilbert RE, Ip DP, Brooks MA. Determination of losartan and its degradants in COZAAR tablets by reversed-phase high-performance thin-layer chromatography. J Pharm Biomed Anal 1998;17:671-7. 
[5]. Williams RC, Alasandro MS, Fasone VL, Boucher RJ, Edwards JF. Comparison of liquid chromatography, capillary electrophoresis and super-critical fluid chromatography in the determination of Losartan Potassium drug substance in Cozaar tablets. J Pharm Biomed Anal 1996;14:1539-46.

[6]. Polinko M, Riffel K, Song H, Lo MW. Simultaneous determination of losartan and EXP3174 in human plasma and urine utilizing liquid chromatography/tandem mass spectrometry. J Pharm Biomed Anal 2003;33:73-84.

[7]. Furtek CI, Lo MW. Simultaneous determination of a novel angiotensin II receptor blocking agent, losartan, and its metabolite in human plasma and urine by high-performance liquid chromatography. J Pharm Biomed Anal 1997;15:1021-9

[8]. Soldner A, Spahn-Langguth H, Mutschler E. HPLC assays to simultaneously determine the angiotensin-AT1 antagonist losartan as well as its main and active metabolite EXP 3174 in biological material of humans and rats. J Pharm Biomed Anal 1998;16:863-73

[9]. Yeung PK, Jamieson A, Smith GJ, Fice D, Pollak PT. Determination of plasma concentrations of losartan in patients by HPLC using solid phase extraction and UV detection. Int J Pharm 2000;204:17-22.

[10]. Iwasa T, Takano T, Hara K, Kamei T. Method for the simultaneous determination of losartan and its major metabolite, EXP-3174, in human plasma by liquid chromatography-electrospray ionization tandem mass spectrometry. J Chromatogr B Biomed Sci Appl $1999 ; 734: 325-30$

[11]. Lastra OC, Lemus IG, Sanchez HJ, Perez RF. Development and validation of an UV derivative spectrophotometric determination of Losartan potassium in tablets. J Pharm Biomed Anal 2003;33:175-80.

[12]. Ansari M, Kazemipour M, Khosravi F, Baradaran M. A comparative study of first-derivative spectrophotometry and highperformance liquid chromatography applied to the determination of losartan potassium in tablets. Chem Pharm Bull 2004;52:1166-70.

[13]. Prabhakar AH, Giridhar R. A rapid colorimetric method for the determination of Losartan potassium in bulk and in synthetic mixture for solid dosage form. J Pharm Biomed Anal 2002;27:861-6.

[14]. Gandhimathi M. HPLC determination of losartan pottassium and ramipril in tablets. Indian drugs 2004;41:120-2.

[15]. International Conference on Harmonization of Technical Requirement for Registration of Pharmaceuticals for Human use, ICH harmonized tripartite Guideline, Validation of Analytical procedures Text and methodology Q2 (R1), 2005.

[16]. R. Jenke, "Chromatographic Method Validation: A review of Current Practices and Procedures. I. General Concepts and Guidelines”, J. Liq. Chrom. and Rel. Technol., vol. 19 (1996), pp. 719-736.

[17]. David M. Bliesner, Validating Chromatographic Methods, (John Wiley and Sons, 2006, p. 72).

[18]. L Gonzalez; RM Alonso; RM Jimenez. Chromatographia., 2000, 52(11-12), 735-740. 